\title{
Characterisation of surface blebbing and membrane vesicles produced by Flavobacterium psychrophilum
}

\author{
Jeannette D. Møller ${ }^{1, *}$, Andrew C. Barnes ${ }^{2,3}$, Inger Dalsgaard ${ }^{1}$, Anthony E. Ellis ${ }^{2}$ \\ ${ }^{1}$ Danish Institute for Fisheries Research, Fish Disease Laboratory, Stigbøjlen 4, 1870 Frederiksberg, Denmark \\ ${ }^{2}$ Fisheries Research Services, The Marine Laboratory, Victoria Road, Aberdeen AB11 9DB, UK \\ ${ }^{3}$ Present address: Centre for Marine Studies, University of Queensland, Brisbane, Queensland 4072, Australia
}

\begin{abstract}
The surface of Flavobacterium psychrophilum was examined by electron microscopy to determine if previous findings of haemagglutination positive $(\mathrm{HA}+)$ and haemagglutination negative (HA-) abilities could be correlated with expression of pili or of a capsular layer. A thin capsular layer was observed in both HA+ and HA- strains but typical pili were absent. However, long, tubular blebs that released membrane vesicles (MVs) into the supernatant were observed on up to $94 \%$ of cells within 1 sample. The surface blebbing was increased for 1 strain following growth on media with restricted iron availability. The MVs had an intact membrane bilayer and were released from blebbing cells of both strains. The protein profiles of MVs, while containing some banding similarity with the profile of outer membrane preparations (OMPs) and of lysed whole cells (WCs), showed several bands that reacted strongly with rabbit anti-whole-cell antisera. Two distinct bands of approximately 62 and $58 \mathrm{kDA}$ were highly expressed in the MVs and not seen in the OMP. MVs contained proteolytic activity towards gelatine but not towards casein and elastin, which were only degraded by live cells. Low molecular weight lipopolysaccharides (LPS) or lipooligosaccharides (LOS) were associated with the MVs. Only the MVs of the HA+ strain possessed haemagglutinin activity. These findings suggest that the $F$. psychrophilum may, through surface blebbing, release antigenic MVs that contain some proteolytic activity and may aid the bacterium in releasing nutrients from its surrounding environment as well as playing a role in impeding the immune response of its host.
\end{abstract}

KEY WORDS: Flavobacterium psychrophilum $\cdot$ Membrane vesicles $\cdot$ Surface blebbing $\cdot$ Electron microscopy

\section{INTRODUCTION}

Flavobacterium psychrophilum has emerged over the last 2 decades as one of the most common causes of bacterial diseases in aquaculture production of rainbow trout Oncorhynchus mykiss in Europe. This fish pathogenic bacterium causes bacterial cold-water disease (BCWD) (Borg 1960), also called rainbow trout fry syndrome (RTFS) (Lorenzen et al. 1997), and is reported to cause high mortality rates and thus substantial economic losses in salmonid aquaculture. F. psychrophilum is a 4 to $8 \mu \mathrm{m}$ long Gram-negative, filamentous rod that lacks flagella and executes motility by gliding. Many bacteria in the Cytophaga-Flavobacterium-Bacteroides cluster exhibit rapid gliding that does not involve pili (Henrichsen \& Blom 1975) and does not seem to be caused by polysaccharide excretion (Lapidus \& Berg 1982, McBride 2001). The exact mechanisms of this type of motility are, however, unclear. The initial adhesion to host cells is an important factor for the colonisation and pathogenicity of a pathogen and we have previously reported the adhesion of F. psychrophilum to depend on a sialic acid-binding lectin present on haemagglutina- 
tion positive $(\mathrm{HA}+)$ strains and absent on HA- strains (Møller et al. 2003). Lectins and haemagglutinins are often expressed on or in connection with the tip of the long, threadlike surface structures known as pili. Flavobacterium (formerly known as Cytophaga as well as Flexibacter) is generally considered to lack pili expression (Henrichsen \& Blom 1975, Pate 1985, McBride 2001) and F. psychrophilum was previously reported to lack pili (Holt et al. 1993, Lorenzen et al. 1997). One member of this group of bacteria, the fish pathogenic agent of bacterial gill disease, Flavobacterium branchiophila (now F. branchiophilum) is, however, reported to possess pili (Heo et al. 1990). A thin, more or less compact slime or capsular layer surrounds F. psychrophilum and may aid in adhesion (Crump et al. 2001). The present study was initiated to determine, by electron microscopy, whether the haemagglutinating ability present in some $F$. psychrophilum strains was correlated with pili or capsular expression.

Several pathogenic Gram-negative bacteria including Escherichia coli O157:H7 (Kolling \& Matthews 1999), Pseudomonas aeruginosa (Kadurugamuwa \& Beveridge 1995), Neisseria gonorrhoeae (Dorward et al. 1989) and Haemophilus influenzae (Kahn et al. 1983) produce external membrane vesicles (MVs), which are spherical, having a diameter of 50 to $250 \mathrm{~nm}$, bilayered, membranous structures constantly being discharged from the surface of cells during growth (Beveridge 1999). MVs may contribute to bacterial pathogenicity as they may contain different types of proteases and toxins (Grenier \& Mayrand 1987, Negrete-Abascal et al. 2000) as well as lipopolysaccharides (LPS) (Kadurugamuwa \& Beveridge 1995, Keenan et al. 2000) that are encapsulated from the periplasm as they bleb off the outer membrane (Kadurugamuwa \& Beveridge 1995). Reports also indicate that DNA may be present in MVs, which may play a role in the exchange of genetic material (Dorward et al. 1989, Kolling \& Matthews 1999, Yaron et al. 2000). Cell wall-degrading enzymes and proteases within vesicles have been suggested to mediate adhesion to host cells (Shoberg \& Thomas 1993), cause aggregation of neighbouring bacterial cells (Grenier \& Mayrand 1987) and through lysis of surrounding host cells release nutrients for growth ( $\mathrm{Li}$ et al. 1998). Exotoxins and extracellular proteases with activity towards gelatine, casein and elastin are described for $F$. psychrophilum (Bertolini et al. 1994, Madsen \& Dalsgaard 1998 and reviewed by Nematollahi et al. 2003). Only some strains of Flavobacterium psychrophilum are able to degrade elastin and many, but not all, of these strains are more virulent than elastin nondegrading strains (Madsen \& Dalsgaard 1998, Madsen \& Dalsgaard 2000). MVs have not previously been described for F. psychrophilum, although Humphrey et al. (1979) described a Flexibacter sp. that produced vesicles and elongated tubular blebs thought to be involved in the gliding motility of this bacterium.

The present paper describes blebbing of Flavobacterium psychrophilum that leads to surface extension and release of MVs. The content of MVs was further characterised by analysing the protein profile as well as DNA and LPS content of isolated MVs.

\section{MATERIALS AND METHODS}

Bacterial strains. Flavobacterium psychrophilum strains included in the present study were the type strain NCMB1947 of serotype $\mathrm{Fp}^{\mathrm{T}}$ and another wellstudied Danish strain, 900406-1/3, representing Serotype Th (Dalsgaard \& Madsen 2000). Previous virulence tests have shown NCMB1947 to be nonpathogenic and 900406-1/3 to be pathogenic in rainbow trout Oncorhyncus mykiss (Madsen \& Dalsgaard 2000). The 2 strains have likewise been shown to be either haemagglutination positive $(\mathrm{HA}+)$ or negative (HA-) respectively (Møller et al. 2003). The strains were maintained in tryptone yeast extract salts $\mathrm{pH} 7.2$ (TYES) (Holt et al. 1993) broth with 15 to $20 \%$ glycerol at $-80^{\circ} \mathrm{C}$, grown at $15^{\circ} \mathrm{C}$ for 36 to $48 \mathrm{~h}$ in TYES broth with agitation and subsequently $200 \mu \mathrm{l}$ were spread on TYES with $1.1 \%$ agar (TYES-A) or $10 \mu \mathrm{l}$ were inoculated into $5 \mathrm{ml}$ TYES broth. Plates and broth cultures were incubated at $15^{\circ} \mathrm{C}$ for $12 \mathrm{~h}, 24 \mathrm{~h}, 2 \mathrm{~d}, 4 \mathrm{~d}$ and $10 \mathrm{~d}$. TYES-A was either supplemented with $10 \%$ heatinactivated (HI) rainbow trout serum $\left(45^{\circ} \mathrm{C}\right.$ for $\left.30 \mathrm{~min}\right)$ or iron-chelated with $50 \mu \mathrm{M}$ 2,2'-dipyridyl (dpd) (Sigma-Aldrich Chemie) to study the surface structures under different nutrient growth conditions.

Electron microscopy (EM). Bacteria for negative staining were gently harvested with a $1 \mu \mathrm{l}$ loop from TYES-A and resuspended in $500 \mu$ lixative buffer (0.07 M cacodylate, $1.2 \%$ glutaraldehyde $\mathrm{pH}$ 7.2) by slow twisting of the loop. Using a phase contrast microscope the bacterial density was adjusted with fixative buffer so that individual cells were visible without having clumps of cells. The fixed cells $(5 \mu \mathrm{l})$ were gently placed onto the shiny side of a formvar-coated 200 mesh copper grid and left for approximately $2 \mathrm{~min}$. Gently touching the side of the grid with a filter paper removed the fluid and the grid was left to dry for $5 \mathrm{~min}$ on filter paper (shiny side up). Staining was performed by placing a drop of $1 \%$ uranyl acetate on the top of the grid and left for approx. 2 min. Fluid was removed as above and the grid left to dry for a minimum of 15 min before EM. Grids were examined on a Phillips EM 300 operated at $80 \mathrm{kV}$.

The number of cells producing MVs or blebs was noted out of 50 neighbouring cells counted in samples 
made following 4 d growth on TYES-A, TYES-A + dpd and TYES-A + HI serum.

Bacteria for thin sections were prepared as described (Jacques \& Foiry 1987). Basically, bacteria were transferred from TYES-A using a $5 \mu$ loop and resuspended in $1 \mathrm{ml}$ whole-cell homologous rabbit antiserum and incubated overnight to stabilise the capsule (Mackie et al. 1979). The cells were washed twice in $0.07 \mathrm{M}$ cacodylate buffer $\mathrm{pH} 7.2(1500 \times g$ for $30 \mathrm{~min})$ before being fixed for $1 \mathrm{~h}$ in fixative buffer, washed 3 times in $0.07 \mathrm{M}$ cacodylate buffer $(1500 \times g$ for $30 \mathrm{~min})$ and incubated with polycationic ferritin $\left(1 \mathrm{mg} \mathrm{ml}^{-1}\right.$; SigmaAldrich) for $30 \mathrm{~min}$ at $20^{\circ} \mathrm{C}$. Cells were then washed twice in $0.07 \mathrm{M}$ cacodylate buffer $(1500 \times g$ for $30 \mathrm{~min})$ and incubated in $\mathrm{OsO}_{4}(4 \%$ in $0.07 \mathrm{M}$ cacodylate buffer) for $3 \mathrm{~h}$ at room temperature. Finally, the cells were dehydrated through a series of ethanol washes before analysis on a Phillips EM 300, operated at $80 \mathrm{kV}$.

Outer membranes. Outer membrane preparations (OMPs) were made by a modification of the method described by Davies (1981). In brief, Flavobacterium psychrophilum cells from a TYES-A plate incubated for $4 \mathrm{~d}$ were harvested in TYES broth and washed in $20 \mathrm{mM}$ Tris- $\mathrm{HCl}$ buffer $\mathrm{pH} 7.2(8000 \times g$ for $10 \mathrm{~min}$ at $4^{\circ} \mathrm{C}$ ). The pellet was resuspended in $20 \mathrm{mM}$ Tris- $\mathrm{HCl}$, 10 mM EDTA, pH 7.2 and the cells disrupted by sonication (Sonicator' XL 2020, Heat Systems-Ultrasonics, with a flat tip, $150 \mathrm{~V}$ for 2 min with $5 \mathrm{~s}$ intervals on ice). Undisrupted cells were removed by centrifugation $\left(8000 \times g\right.$ for $10 \mathrm{~min}$ at $\left.4^{\circ} \mathrm{C}\right)$ and the supernatant subjected to high-speed centrifugation $(20590 \times g$ for $60 \mathrm{~min}$ at $4^{\circ} \mathrm{C}$ ). The pellet containing both cytoplasmic membrane and outer membrane material was resuspended in $0.5 \%$ Sarkosyl (Sigma-Aldrich) in $20 \mathrm{mM}$ Tris-HCl pH 7.2 and kept on ice for $20 \mathrm{~min}$ with light agitation. High-speed centrifugation $(20590 \times g$ for $60 \mathrm{~min}$ at $4^{\circ} \mathrm{C}$ ) sedimented the outer membrane materials from the dissolved cytoplasmic membrane materials in the supernatant. The pellet was resuspended in $0.5 \%$ Sarkosyl in $20 \mathrm{mM}$ Tris- $\mathrm{HCl} \mathrm{pH} 7.2$ and kept on ice for $20 \mathrm{~min}$. The outer membrane materials were sedimented $\left(20590 \times g\right.$ for $60 \mathrm{~min}$ at $\left.4^{\circ} \mathrm{C}\right)$ and washed twice in $500 \mu$ phosphate buffered saline (PBS) before the pellet was finally resuspended in $200 \mu \mathrm{PBS}$ and stored at $-20^{\circ} \mathrm{C}$ until use.

Membrane vesicles. MVs were basically purified as described (Kadurugamuwa \& Beveridge 1995). In brief, Flavobacterium psychrophilum was grown on TYES-A for $4 \mathrm{~d}$ before cells were harvested in TYES. Following centrifugation $\left(6000 \times g\right.$ for $10 \mathrm{~min}$ at $\left.4^{\circ} \mathrm{C}\right)$ the supernatant was passed through a $0.22 \mu \mathrm{m}$ filter and the MVs collected by centrifugation $(20590 \times \mathrm{g}$ for $99 \mathrm{~min}$ at $4^{\circ} \mathrm{C}$ ). The pellet was washed twice in $50 \mathrm{mM}$ 4-(2-hydroxyethyl)piperazine-l-ethanesu- lonic acid (HEPES, Fluka BioChemika) and resuspended in $250 \mu \mathrm{l}$ HEPES (50 mM) with $0.05 \mathrm{M}$ Dithiothreitol (DTT, Sigma-Aldrich). The MVs preparation was checked for presence of F. psychrophilum cells by plating on TYES-A and by negative staining and transmission electron microscopy (TEM). Isolated vesicles were kept at $-20^{\circ} \mathrm{C}$ until further analysis when they were lysed with $3 \%$ SDS pH 12.6 for DNA analysis or by sonication for protein and protease analysis.

Sodium dodecyl sulphate polyacrylamide gel electrophoresis (SDS-PAGE). The protein content of MVs, whole cells (WCs) sonicated as above and the outer membrane preparations (OMP) was determined using a BCA protein assay kit (Pierce) and diluted to $100 \mu \mathrm{g}$ protein $\mathrm{ml}^{-1}$ before $15 \mu \mathrm{l}$ of each sample were electrophoresed on a NuPAGE 4 to $12 \%$ SDS-PAGE gel $\left(\right.$ Invitrogen ${ }^{\mathrm{TM}}$ ). Proteins were stained with a Coomassie G-250 stain (SimplyBlue ${ }^{\mathrm{TM}}$ Safestain, Invitrogen).

MVs were analysed for lipopolysaccharides (LPS) or lipooligosaccharides (LOS) on a NuPAGE $12 \%$ SDSPAGE gel (Invitrogen ${ }^{\mathrm{TM}}$ ) together with LPS/LOS purified from WCs using Polymyxin B resin as described (Valverde et al. 1997). Gels were fixed and then oxidised with periodic acid before silver staining as described (Tsai \& Frasch 1982).

Western blot analysis. For western blot analysis $7.5 \mu \mathrm{l}$ of each sample (diluted to $100 \mu \mathrm{g}$ protein $\mathrm{ml}^{-1}$ ) were separated as described above. Separated proteins were transferred to a nitrocellulose membrane for $1 \mathrm{~h}$ at constant $30 \mathrm{~V}$, rinsed in $\mathrm{dH}_{2} \mathrm{O}$ and blocked (PBS $+1 \%$ skim milk) for $1 \mathrm{~h}$ at room temperature. The membrane was washed in PBS + 0.05\% Tween 20 and incubated with a 1:200 dilution of polyclonal rabbit-antiFlavobacterium raised against whole cells of either NCMB1947 or 900406-1/3 (Dalsgaard \& Madsen 2000) for $1 \mathrm{~h}$ at room temperature before the membrane was washed again. A peroxidase labelled goat anti-rabbit immunoglobulin, IgG (DAKO) was used as secondary antibody and incubated at room temperature for $1 \mathrm{~h}$ before any specific binding was visualised using a 3,3'diaminobenzidine substrate (Sigma-Aldrich).

Protease activity. Protein degrading abilities were analysed on TYES-A containing gelatine $(0.6 \%)$, casein $(0.5 \%)$ or elastin $(0.1 \%)$ as described (Madsen \& Dalsgaard 1998). Wells (4 $\mathrm{mm}$ in diameter) were punched in the plates and filled with $20 \mu \mathrm{l}$ (gelatine and casein) or $40 \mu \mathrm{l}$ (elastin) of isolated MVs or sonicated MVs. Live whole cells were plated as positive control. Plates were incubated for a minimum of $7 \mathrm{~d}$ at $15^{\circ} \mathrm{C}$ before noting the appearance of clear zones.

Haemagglutination. The capacity of the MVs to haemagglutinate rainbow trout erythrocytes was evaluated as described (Møller et al. 2003) by mixing $50 \mu \mathrm{l} 3 \%$ rainbow trout erythrocyte suspension with $50 \mu \mathrm{l}$ MVs preparation serially diluted 2-fold from 1:2 
to $1: 1024$. Aggregation of erythrocytes was noted after 5 min incubation at $15^{\circ} \mathrm{C}$.

DNA isolation. MVs were analysed for DNA following DNA'se I (Sigma-Aldrich) treatment to hydrolyse any surface-associated DNA or free DNA. Both DNA'se-treated MVs and WCs were lysed at $56^{\circ} \mathrm{C}$ for 30 min with $3 \%$ SDS pH 12.6 before the presence of plasmid DNA was tested using the GeneElute Kit (Sigma-Aldrich) and chromosomal DNA isolated as described (Madsen \& Dalsgaard 2000).

\section{RESULTS}

\section{Electron microscopy}

The negative staining of Flavobacterium psychrophilum strain 900406-1/3 and NCMB1947 showed no traditional pili structures although surface blebbing and MVs were observed in all samples (Fig. 1A-D). The MVs and tubular blebs varied from 0.1 to $0.8 \mu \mathrm{m}$ in length and were up to $100 \mathrm{~nm}$ in diameter. Occasionally the MVs would also appear as pearlstrings with numerous circular structures adhering to each other (Fig. 1B). The tubular blebbing structures seemed to break off the bacterial surface easily, resulting in only short stubs sticking out from the surface and, thus, gentle handling of samples, e.g. avoiding centrifugation, was necessary. The supernatant of sedimented bacteria contained circular MVs as well as elongated pieces of broken off blebs (Fig. 1C). An intact membrane bilayer was observed on MVs as they were released through blebbing (Fig. 1D). Individual cells that neither expressed surface blebbing nor showed signs of MVs release were observed within all preparations (Fig. 1E). The 2 strains, 900406-1/3 and NCMB1947, were examined following growth in TYES broth, on normal TYES-A plates, in TYES-A with added 10\% HI serum and in TYES-A with dpd. The percentage of bacterial cells expressing surface blebbing was generally high, with expression rates varying from $46 \%$ to as high as $94 \%$ (Table 1). Strain 900406-1/3 had a very high expression on all tested media whereas strain NCMB1947 only showed a very high degree of expression following growth on media containing dpd. The lengths of the structures varied, and were generally longer on plates with iron
Table 1. Percentage of cells expressing surface blebbing following growth for $4 \mathrm{~d}$ on normal TYES-A and TYES-A supplemented with HI rainbow trout serum or iron-chelated with dpd

\begin{tabular}{|lccc|}
\hline & TYES-A & $\begin{array}{c}\text { TYES-A + } \\
\text { serum }(10 \%)\end{array}$ & $\begin{array}{c}\text { TYES-A + } \\
\text { dpd }\end{array}$ \\
\hline NCMB1947 & $46 \%$ & $46 \%$ & $94 \%$ \\
$900406-1 / 3$ & $92 \%$ & $80 \%$ & $72 \%$ \\
\hline
\end{tabular}

availability restricted with either dpd or with serum, and shorter on bacteria isolated from TYES-A. Cells grown in liquid broth mainly expressed shorter and more circular structures. Comparing the 2 F. psychrophilum strains, 900406-1/3 generally expressed longer structures than the type strain NCMB1947. Blebbing and MVs production were observed in samples of $12 \mathrm{~h}, 24 \mathrm{~h}$ and of 2, 4 or $10 \mathrm{~d}$ of age.

Both Flavobacterium psychrophilum strains expressed a small amount of capsular layer scattered around the cell (Fig. 2A,B). A slight increase in the

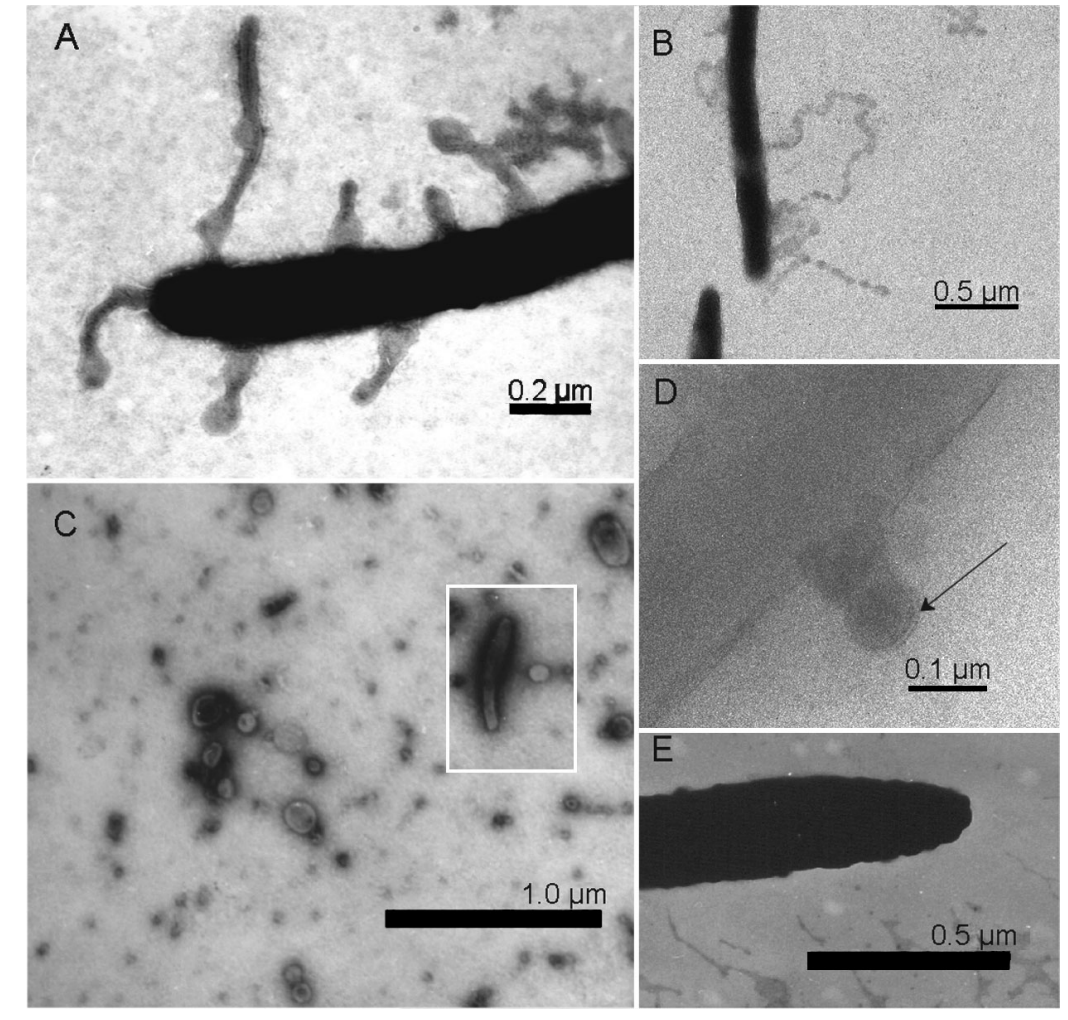

Fig. 1. Flavobacterium psychrophilum. Transmission electron microscopic (EM) visualisation of $F$. psychrophilum stained with $1 \%$ uranyl acetate (A) NCMB1947, 10 d on TYES-A iron chelated with 2'2dipyridyl; (B) 900406-1/3, $10 \mathrm{~d}$ on normal TYES-A, showing membrane vesicles adhering to each other like pearls on a string; (C) circular and elongated (insert) MVs in the supernatant of $900406-1 / 3$ grown for $4 \mathrm{~d}$ in TYES; (D) vesicle on the surface of 900406-1/3; note the intact membrane bilayer (arrow); (E) cell without blebbing or MVs expression; NCMB1947, 10 d on normal TYES-A 
amount of visible capsular material was observed when agar was supplemented with $10 \%$ HI serum (Fig. 2C,D).

\section{SDS-PAGE and western blotting}

The protein profiles of MVs, OMPs and WCs analysed in SDS-PAGE (Fig. 3) generally showed similar banding patterns with a few distinctly different protein bands. Three bands of approximately 42, 104 and $112 \mathrm{kDA}$ were present in all preparations. The MVs profiles of both strains showed 2 very distinct bands of approximately 58 and $62 \mathrm{kDA}$ as well as 2 bands of approximately 52 and $54 \mathrm{kDA}$. The MVs of NCMB1947 had 2 bands in the 140 to $180 \mathrm{kDa}$ region compared to 1 band in 900406-1/3, and 900406-1/3 expressed a double band of approximately 42 to $43 \mathrm{kDA}$ compared to a single band in NCMB1947. Variations between the 2 strains were observed in the 64 to $100 \mathrm{kDA}$ region of all preparations. The OMPs showed variation in the 64 to $100 \mathrm{kDA}$ region and strain variation in the positions of bands in the 46 to $54 \mathrm{kDA}$ region.

The antigenic profile of western blot analysis (Fig. 4) showed that almost all antigenic bands in the WCs were also present in the MVs of both strains and 2 bands of approximately 62 and $58 \mathrm{kDA}$ were broader and more intensely stained in the MVs. The antigenic profile of the 2 strains was similar in the MVs and only a few differences were seen in the OMPs. The OMPs of both strains were shown to generally express fewer antigenic bands than the MVs and the WCs.

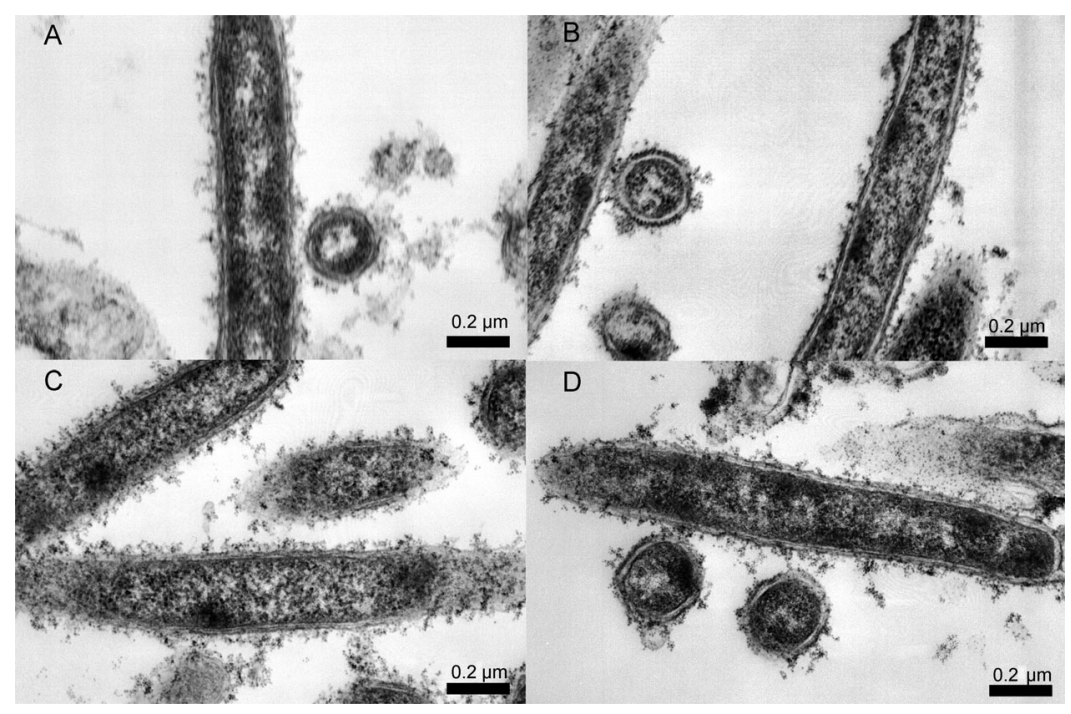

Fig. 2. Flavobacterium psychrophilum. Thin sections of antibody stabilised and ferritin-labelled capsular layers of $F$. psychrophilum strain 900406-1/3 (A,C) and NCMB1947 (B,D) grown on TYES-A (A,B) or on TYES-A supplemented with HI rainbow trout serum $(\mathrm{C}, \mathrm{D})$

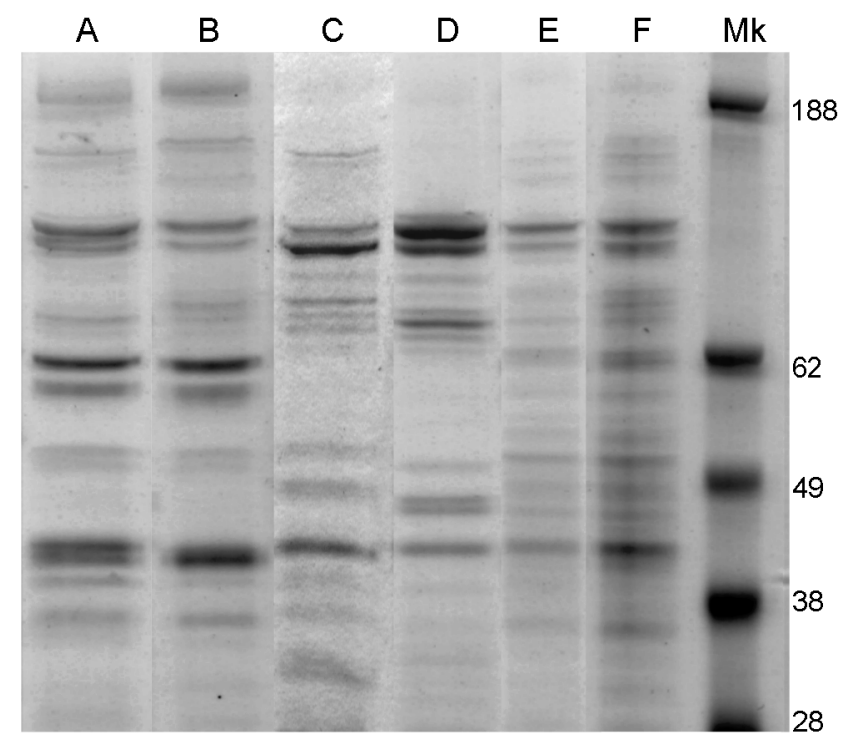

Fig. 3. SDS-PAGE protein profiles of MVs from (A) 900406$1 / 3$ and (B) NCMB1947, and OMPs from (C) 900406-1/3 and (D) NCMB1947. WC from (E) 900406-1/3 and (F) NCMB1947. Molecular-mass marker $(\mathrm{Mk})$ indicated on the right

A single broad low-molecular band of approximately $14 \mathrm{kDA}$ was observed in the MVs of both strains when the SDS-PAGE were oxidised and silver stained to show carbohydrate properties of LPS or LOS (Fig. 5). A similar band of ca. $14 \mathrm{kDA}$, as well as a broad high molecular band most likely constituted of several bands of $>60 \mathrm{kDA}$, was found when LPS/LOS were purified from WCs.

\section{Protease activity}

Isolated MVs of both strains showed proteolytic activity towards gelatine with clear zones appearing after $7 \mathrm{~d}$ incubation. Casein and elastin were not degraded by the MVs of either strain. No difference was observed when MVs were lysed by sonication to release possible internal proteases. Both gelatine and casein were degraded when live cells of both strains were grown on the plates, and elastin was degraded only by live 900406-1/3 cells.

\section{Haemagglutination}

The MVs of NCMB1947 had high agglutinating properties with a dilution of 1:256 still causing haemagglutination. MVs isolated from 900406-1/3 had no haemagglutinating abilities. 


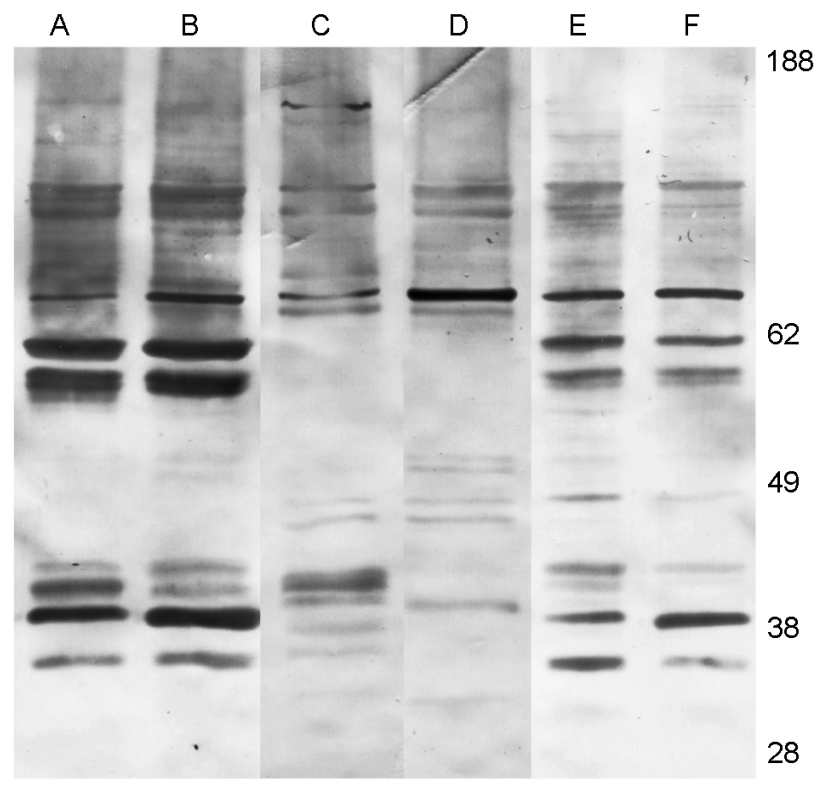

Fig. 4. Western blot analysis of (A) MVs from 900406-1/3; (B) MVs from NCMB1947; (C) OMPs from 900406-1/3; (D) OMPs from NCMB1947; (E) WC from 900406-1/3 and (F) WC from NCMB1947 using either rabbit-anti-Flavobacterium psychrophilum 900406-1/3 serum $(\mathrm{A}, \mathrm{C}, \mathrm{E})$ or rabbitanti-F. psychrophilum NCMB1947 serum (B,D,F). Molecularmass marker indicated on the right

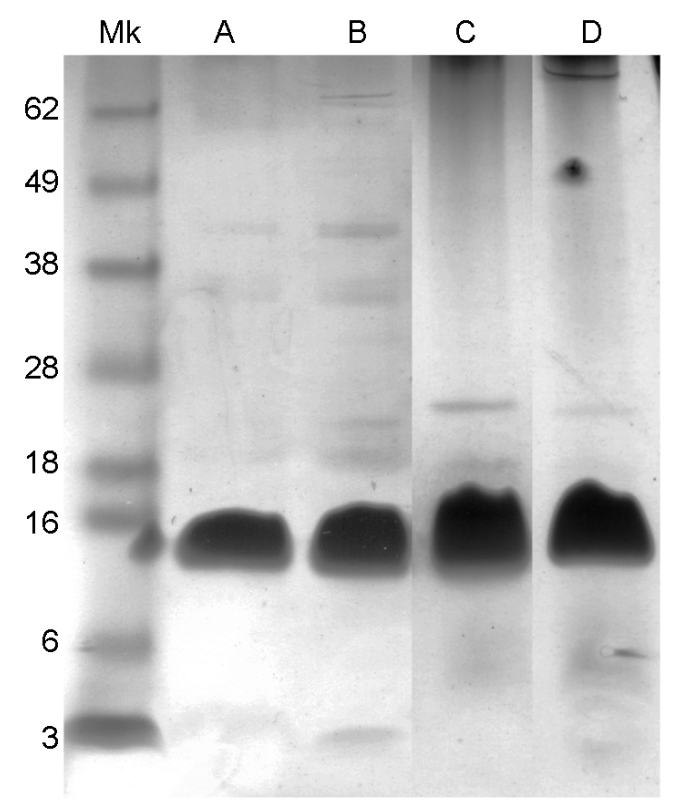

Fig. 5. SDS-PAGE oxidised with periodic acid before silver staining to visualise carbohydrate properties of lipopolysaccharides (LPS) or lipooligosaccharides (LOS) in (A) WC of NCMB1947; (B) WC of 900406-1/3; (C) MVs of NCMB1947 and (D) MVs of 900406-1/3. Molecular-mass marker (Mk) indicated on the left

\section{DNA isolation}

No DNA could be detected on either the surface or inside the MVs following lysis.

\section{DISCUSSION}

Flavobacterium psychrophilum strains have previously been divided into HA+ and HA- groups (Møller et al. 2003). In the present work, 2 strains (1 HA+ and 1 HA-) were studied by EM for the presence of pili and varying capsular layer expression. No pili expression was observed on either strain, corresponding with previous studies (Holt et al. 1993, Lorenzen et al. 1997). The difference in adhesion between $\mathrm{HA}+$ and HAstrains is therefore not linked to pili expression. A thin, irregular and scattered layer of capsule surrounded $F$. psychrophilum, but was not as dense or regular as has been observed for many other capsule-producing bacteria, such as the closely related Flavobacterium columnare (Decostere et al. 1999) and exposure to serum only increased the capsular density slightly. No clear variation in the capsular layer was seen between the 2 strains, indicating that the capsular layer of $F$. psychrophilum is not involved in the haemagglutination. The HA abilities have previously been shown to be unaffected by destruction of capsular material with sodium periodate (Møller et al. 2003).

EM of negatively stained Flavobacterium psychrophilum did, however, reveal surface blebbing that released MVs into the surrounding environment. Surface blebbing describes the extrusion of the outer membrane that leads to shedding of MVs, which are prominent in many Gram-negative bacteria and may contain virulence factors such as proteases, toxins, LPS and even DNA (Grenier \& Mayrand 1987, Kadurugamuwa \& Beveridge 1995, Beveridge 1999, Keenan et al. 2000, Yaron et al. 2000, Hayashi et al. 2002). The percentage of blebbing F. psychrophilum cells was generally very high, but for strain NCMB1947 a marked increase was observed in cultures grown under iron limitation produced by supplementing the medium with dipyridyl or serum, indicating that certain stress factors may increase surface blebbing and MVs release. The release of MVs in Pseudomonas aeruginosa increases threefold after brief exposure to gentamicin (Kadurugamuwa \& Beveridge 1995), and under hemin limitation, Bacteroides gingivalis increases surface blebbing, releases large numbers of MVs and seems to become less virulent (McKee et al. 1986). Li et al. (1998) found an increased number of MVs in the mid-exponential growth phase and suggested that this corresponds with the extra need for nutrients during this period of high metabolic 
activity as the culture is growing and dividing. However, in the present work, blebbing cells were found next to non-blebbing cells in samples from the same cultures. Other nutrient conditions that might mimic in vivo conditions to a higher degree as well as exposure to antibiotics should be studied to shed light on factors influencing the surface blebbing and release of MVs of F. psychrophilum. The MVs of the HA+ strain, but not of the HA- strain, caused haemagglutination indicating that MVs express the same adhesive abilities as the WC. A sialic-acid binding lectin mediates the haemagglutination of F. psychrophilum and is mainly expressed on strains of the $\mathrm{Fp}^{\mathrm{T}}$ serotype (Møller et al. 2003), which is generally considered non-virulent in rainbow trout. The absence of haemagglutinin expression have been suggested to influence pathogenicity by providing the HA-strains with increased resistance to complement-mediated bacteriolysis as shown for fimbriae negative strains of Haemophilus influenzae Type b (Miyazaki et al. 1999).

The SDS-PAGE profiles revealed that the polypeptide patterns of the MVs shared similarities, but were not identical with those of the OMPs and the WCs. MVs of both strains showed 2 distinct bands of approximately $62 \mathrm{kDA}$ and $58 \mathrm{kDA}$ that were absent in the OMPs profile. Two metalloproteases, Fpp1 and Fpp2, with a molecular mass of approximately 55 and $62 \mathrm{kDA}$ respectively, have recently been described for Flavobacterium psychrophilum (Secades et al. 2001, 2003). These metalloproteases function as hydrolytic enzymes capable of degrading proteins of both connective and muscular tissue. Furthermore, Merle et al. (2003) characterised a glycoprotein of approximately $60 \mathrm{kDA}$, designated P60, as one of the major cellular antigens of $F$. psychrophilum. It is possible that the 2 protein bands of approx. 62 and $58 \mathrm{kDA}$ found in the MVs in this study could represent any 2 of these previously described proteins, but further studies are required. Western blot analysis showed a high content of antigenic proteins in the MVs, including the 58 and $62 \mathrm{kDA}$ proteins, which were not expressed in the OMPs. A high content of antigenic proteins in the MVs can influence the pathogenicity of the bacteria. First, it is likely that these small units function as transport vehicles of hydrolytic enzymes that would enhance the release of nutrients through degradation of host tissue or lyses of surrounding bacteria as described for several Gram-negative bacteria (Li et al. 1998). Alternatively, or perhaps as an added bonus, the MVs will compete for antibodies and thus impede the specific immune defence as suggested for Bacteroides gingivalis (Grenier \& Mayrand 1987). F. psychrophilum vaccination trials have mainly used formalin-killed bacterial whole cells, giving some reduced mortality in vaccinated groups (reviewed by Nematollahi et al.
2003) but recently vaccines based on the outer membrane fraction were reported to induce higher protection than whole-cell-based vaccines (Rahman et al. 2002). The expression of several antigenic proteins in the MVs that are not expressed in the OMP of F. psychrophilum could make MVs an interesting vaccine candidate. Purified MVs have been shown to elicit a safe and effective means of vaccination against e.g. Neisseria meningitidis Group B infections (Arigita et al. 2004).

All Flavobacterium psychrophilum strains degrade proteins including gelatine and casein but only some strains degrade elastin (Madsen \& Dalsgaard 1998, Dalsgaard \& Madsen 2000). The ability to degrade elastin has been suggested as a virulence factor for $F$. psychrophilum, as elastin non-degrading strains (including NCMB1947) show reduced virulence compared to most elastin degrading strains (including 900406-1/3) (Madsen \& Dalsgaard 2000). MVs were shown in this study to degrade gelatine but not casein and elastin. A lack of elastase activity in MVs of Pseudomonas aeruginosa has been reported and it was suggested that some MV-entrapped proteases remain inactive unless they cross the membrane of the vesicle (Kadurugamuwa \& Beveridge 1995). Protease production is regulated by numerous factors and the protease content of MVs may thus be regulated by factors such as nutrient availability and growth phase. Further characterisation of the protease activity, perhaps under in vivo conditions, is necessary to clarify the importance of MVs in the pathogenesis of F. psychrophilum.

The LPS of Flavobacterium psychrophilum comprises both low-molecular-mass oligosaccharides of approximately $16 \mathrm{kDA}$ and high-molecular-mass $\mathrm{O}$ antigens (Crump et al. 2001). In this study the lowmolecular-mass oligosaccharides were detected in the MVs and WC lysate of both F. psychrophilum strains and the high-molecular-mass $O$ antigens were detected only in the WCs. B-band LPS (high-molecularmass $\mathrm{O}$ antigens) and A-band (lower-molecular-mass O antigens) are present in the MVs of Pseudomonas aeruginosa. However, the content of these 2 LPS types in the MVs are influenced by gentamicin exposure; during normal growth MVs contain only B-band LPS while, following exposure to gentamicin, the MVs mainly contain A-band LPS (Kadurugamuwa \& Beveridge 1995, Beveridge 1999). Whether exposure to gentamicin or other cell wall active antibiotics have a similar effect on F. psychrophilum LPS, remains to be elucidated.

The exact mechanisms of the gliding motility observed for numerous bacteria within the CytophagaFlavobacterium-Bacteroides (CFB) cluster, including F. psychrophilum, is not known. The possibility that the blebbing structures are polysaccharide extrusions 
involved in this motility cannot be excluded but is minimised by the overall similarity of the protein profile with that of the OMP as well as the general perception that CFB gliding is not caused by polysaccharide excretion (Lapidus \& Berg 1982, McBride 2001).

The evidence presented here shows that the fish pathogen Flavobacterium psychrophilum extrudes blebs and releases MVs from its surface and that these MVs contain important antigenic proteins. These features could, however, not be directly linked to the virulence of F. psychrophilum as no major differences were seen in the blebbing and release of MVs from the virulent and the non-virulent strain. The blebbing and release of MVs may, therefore, be considered as a general feature of the F. psychrophilum surface that may play a possible role in the interaction with the host immune system, as indicated by the high content of antigenic proteins.

Acknowledgements. This work was supported by the Danish Institute for Fisheries Research and The Danish Research Academy. The technical assistance with EM by Mr. Kevin McKenzie at the Zoology Department, Aberdeen University, Scotland, and by Mrs. Lisbeth Haukrogh at the Botanical Institute at Copenhagen University, Denmark, is highly appreciated.

\section{LITERATURE CITED}

Arigita C, Jiskoot W, Westdijk J, van Ingen C, Hennink WE, Crommelin DJA, Kersten GFA (2004) Stability of monoand trivalent meningococcal outer membrane vesicle vaccines. Vaccine 22:629-642

Bertolini JM, Wakabayashi H, Watral VG, Whipple MJ, Rohovec JS (1994) Electrophoretic detection of proteases from selected strains of Flexibacter psychrophilus and assessment of their variability. J Aquat Anim Health 6: 224-233

Beveridge TJ (1999) Structures of Gram-negative cell walls and their derived membrane vesicles. J Bacteriol 181: 4725-4733

Borg, AF (1960) Studies on myxobacteria associated with diseases in salmonid fishes. J Wildl Dis 8:1-85

Crump EM, Perry MB, Clouthier SC, Kay WW (2001) Antigenic characterization of the fish pathogen Flavobacterium psychrophilum. Appl Environ Microbiol 67: 750-759

Dalsgaard I, Madsen L (2000) Bacterial pathogens in rainbow trout, Oncorhynchus mykiss (Walbaum), reared at Danish freshwater farms. J Fish Dis 23:199-209

Davies RL (1981) Outer membrane protein profiles of Yersinia ruckeri. Vet Microbiol 26:125-140

Decostere A, Haesebrouck F, Van Driessche E, Charlier G, Ducatelle R (1999) Characterization of the adhesion of Flavobacterium columnare (Flexibacter columnaris) to gill tissue. J Fish Dis 22:465-474

Dorward DW, Garon CF, Judd RC (1989) Export and intercellular transfer of DNA via membrane blebs of Neisseria gonorrhoeae. J Bacteriol 171:2499-2505
Grenier D, Mayrand D (1987) Functional characterization of extracellular vesicles produced by Bacteroides gingivalis. Infect Immun 55:111-117

Hayashi J-i, Hamada N, Kuramitsu HK (2002) The autolysin of Porphyromonas gingivalis is involved in outer membrane vesicle release. FEMS Microbiol Letters 216: $217-222$

Henrichsen J, Blom J (1975) Examination of fimbriation of some Gram-negative rods with and without twitching and gliding motility. Acta Pathol Microbiol Scand 83:161-170

Heo G-J, Wakabayashi H, Watabe S (1990) Purification and characterization of pili from Flavobacterium branchiophila. Fish Pathol 25:21-27

Holt RA, Rohovec JS, Fryer JL (1993) Bacterial coldwater disease. In; Inglis V, Roberts RJ, Bromage NR (eds) Bacterial diseases of fish. Blackwell Scientific Publications, Oxford, p 3-23

Humphrey BA, Dickson MR, Marshall KC (1979) Physicochemical and in situ observations on the adhesion of gliding bacteria to surfaces. Arch Microbiol 120:231-238

Jacques M Foiry B (1987) Electron microscopic visualization of capsular material of Pasteurella multocida Types A and D labelled with polycationic ferritin. J Bacteriol 169: $3470-3472$

Kadurugamuwa JL, Beveridge TJ (1995) Virulence factors are released from Pseudomonas aeruginosa in association with membrane vesicles during normal growth and exposure to gentamicin: a novel mechanism of enzyme secretion. J Bacteriol 177:3998-4008

Kahn ME, Baray F, Smith HO (1983) Transformasomes: specialized membranous structures that protect DNA during Haemophilus transformation. Proc Natl Acad Sci USA 80:6927-6931

Keenan J, Day T, Neal S, Cook B, Perez-Perez G, Allardyce R, Bagshaw P (2000) A role for the bacterial outer membrane in the pathogenesis of Helicobacter pylori infection. FEMS Microbiol Letters 182:259-264

Kolling GL, Matthews KR (1999) Export of virulence genes and shiga toxin by membrane vesicles of Escherichia coli O157:H7. Appl Environ Microbiol 65:1843-1848

Lapidus IR, Berg HC (1982) Gliding motility of Cytophaga sp. Strain U67. J Bacteriol 151:384-398

Li Z, Clarke AJ, Beveridge TJ (1998) A major autolysin of Pseudomonas aeroginosa: subcellular distribution, potential role in cell growth and division, and secretion in surface membrane vesicles. J Bacteriol 178:2479-2488

Lorenzen E, Dalsgaard I, Bernardet J (1997) Characterization of isolates of Flavobacterium psychrophilum associated with coldwater disease or rainbow trout fry syndrome I: phenotypic and genomic studies. Dis Aquat Org 31:197-208

Mackie EB, Brown KN, Lam J, Costerton JW (1979) Morphological stabilization of capsules of Group B streptococci, Types Ia, Ib, II, and III, with specific antibody. J Bacteriol 138:609-617

Madsen L, Dalsgaard I (1998) Characterization of Flavobacterium psychrophilum: comparison of proteolytic activity and virulence of strains isolated from rainbow trout (Oncorhynchus mykiss) In: Barnes AC, Davidson GA, Hiney MP, McIntosh D (eds) Methodology in fish diseases research. Fish Res Services, Aberdeen, p 45-52

Madsen L, Dalsgaard I (2000) Comparative studies of Danish Flavobacterium psychrophilum isolates: ribotypes, plasmid profiles, serotypes and virulence. J Fish Dis 23: 211-218

McBride MJ (2001) Bacterial gliding motility: multiple mechanisms for cell movement over surfaces. Annu Rev Microbiol 55:49-75 
McKee AS, McDermid AS, Baskerville A, Dowsett AB, Ellwood DC, Marsh PD (1986) Effect of hemin on the physiology and virulence of Bacteriodes gingivalis W50. Infect Immun 52:349-355

Merle C, Faure D, Urdaci M-C, Le Hénaff M (2003) Purification and characterization of a membrane glycoprotein from the fish pathogen Flavobacterium psychrophilum. J Appl Microbiol 94:1120-1127

Miyazaki S, Tateda K, Matsumoto T, Furuya N, Yamauchi K (1999) The pathogenic role of fimbriae of Haemophilus influenzae Type $\mathrm{b}$ in murine bacteraemia and meningitis. J Appl Bacteriol 48:383-388

Møller JD, Larsen JL, Madsen L, Dalsgaard I (2003) Involvement of a sialic acid-binding lectin with haemagglutination and hydrophobicity of Flavobacterium psychrophilum. Appl Environ Microbiol 69:5275-5280

Negrete-Abascal E, Garcia RM, Reyes ME, Godínez D, de la Garza M (2000) Membrane vesicles released by Actinobacillus pleuropneumoniae contain proteases and Apx toxins. FEMS Microbiol Letters 191:109-113

Nematollahi A, Decostere A, Pasmans F, Haesebrouck F (2003) Flavobacterium psychrophilum infections in salmonid fish. J Fish Dis 26:563-574

Pate JL (1985) Gliding motility in Cytophaga. Microbiol Sci 2: 289-295

Rahman MH, Kuroda A, Dijkstra JM, Kiryu I, Nakanishi T,

Editorial responsibility: David Bruno,

Aberdeen, UK
Ototake M (2002) The outer membrane fraction of Flavobacterium psychrophilum induces protective immunity in rainbow trout and ayu. Fish Shellfish Immunol 12: 169-179

Secades P, Alvarez B, Guijarro JA (2001) Purification and characterization of a psychrophilic, calcium-induced, growth-phase-dependent metalloprotease from the fish pathogen Flavobacterium psychrophilum. Appl Environ Microbiol 67:2436-2444

Secades P, Alvarez B, Guijarro JA (2003) Purification and properties of a new psychrophilic metalloprotease (Fpp2) in the fish pathogen Flavobacterium psychrophilum. FEMS Microbiol Letters 226:273-279

Shoberg RJ, Thomas DD (1993) Specific adherence of Borrelia burgdorferi extracellular vesicles to human endothelial cells in culture. Infect Immun 61:3892-3900

Tsai C-M, Frasch CE (1982) A sensitive silver stain for detecting lipopolysccharides in polyacrylamide gels. Anal Biochem 119:115-119

Valverde C, Hozbor DF, Lagares A (1997) Rapid preparation of affinity-purified lipopolysaccharide samples for electrophoretic analysis. Biotechniques 22:230-232

Yaron S, Kolling GL, Simon L, Matthews KR (2000) Vesiclesmediated transfer of virulence genes from Escherichia coli O157:H7 to other enteric bacteria. Appl Environ Microbiol $66: 4414-4420$

Submitted: April 20, 2004; Accepted: October 6, 2004 Proofs received from author: April 7, 2005 